\title{
Quality evaluation of minoxidil topical solutions obtained from magistral pharmacies
}

\author{
Karen Nicolau Dartora ${ }^{\mathrm{b} \#}$, Paula Cristina Bona ${ }^{\mathrm{b} \#}$, Francielli Lima dos Santos ${ }^{\mathrm{a}}$, Paula Bianchetti ${ }^{\mathrm{b}, \mathrm{c}}$, Renata Vidor Contri ${ }^{\mathrm{a}, \mathrm{b} *}$. \\ ${ }^{a}$ Faculdade de Farmácia, Universidade Federal do Rio Grande do Sul, Porto Alegre, Brazil; ${ }^{b}$ Curso de Farmácia, \\ Universidade do Vale do Taquari, Lajeado, Brazil; ${ }^{c}$ Curso de Fisioterapia, Universidade de Santa Cruz do Sul, Santa Cruz. \\ do Sul, Brazil. \#both authors contributed equally
}

*Corresponding author: renata.contri@ufrgs.br

The objective of this study was to evaluate quality parameters of magistral topical solutions containing minoxidil (A, B and C), comparing the results with the ones obtained for the industrial formulation. Organoleptic tests, evaluation of the $\mathrm{pH}$ and density, centrifuge test, drug content determination, comparison of indicated dosage and in vitro follicular penetration of minoxidil were performed. Regarding the organoleptic properties, differences in color and viscosity were observed between the magistral (composed of minoxidil sulfate) and the industrial formulations (composed of minoxidil base). For pH values, the magistral solutions presented considerably more acidic $\mathrm{pH}$, compared to the industrial sample. For the density test, the samples with the highest ethanol percentages (B and C) presented lower density. In the centrifuge test, none of the samples showed changes. Considering the drug content test, only the industrial sample and the magistral sample C showed drug percentage within the expected (90-110\%), indicating lack of correction factor determination by the magistral pharmacies. Furthermore, it was observed that the dosage indicated by the magistral pharmacies do not correspond to the dose indicated by the industry, being significantly lower. All topical solutions tested presented hair follicle penetration of minoxidil, without statistical difference. The results indicate that there is a failure in the magistral pharmacies regarding the production and the indication of dosage of minoxidil topical solutions.

Keywords: Alopecia; minoxidil; magistral formulas; good manufacturing procedures; quality control.

\section{Introduction}

Alopecia, popularly known as baldness, is characterized by the fall of the hair. It is a chronic inflammatory dermatological disease that affects hair follicles [1]. Its etiology and development are not fully known, however, it may be linked to genetic, environmental and/or autoimmune disorders. Although it has few harmful effects on the body, alopecia can lead to psychological problems such as anxiety and depression. Nowadays, alopecia affects women almost as much as men. Different types of alopecia develop different characteristics and need specific treatments, since they present different causes. Among the most common acquired alopecia, the androgenetic alopecia can be mentioned, which is caused by genetic factors as well as androgen hormones and their metabolites $[1,2,3,4]$.

Minoxidil is one of the most used drugs to treat alopecia. It was initially indicated as a hypotensive agent for patients with refractory oral hypertension. In the treatment of alopecia, it is used as a topical solution acting by a vasodilatory effect and by keeping the hair follicle in the anagen phase longer $[3,4,5]$. Combined use of minoxidil with other drugs enhances its effect and brings better results for patients undergoing treatment [1].

Topical solutions containing minoxidil can be obtained from magistral pharmacies, allowing the customization of the drug concentration and the formulation components according to the patient's needs, besides presenting lower costs when compared to the industrial product. However, considering that the magistral pharmacies do not perform as many quality control assays in their products as the pharmaceutical industries, magistral formulas may present quality deviations affecting their therapeutic effects as well as their safety [6,7]. For liquid formulations, appearance, organoleptic characteristics, $\mathrm{pH}$ and volume determinations should be performed for each formula produced by the magistral pharmacy, while the drug content determination should be evaluated for at least one formulation every three months [8].

In view of the exposed, this study aimed to evaluate the quality parameters of minoxidil topical solutions from magistral pharmacies, through physicochemical assays, evaluation of the indicated dose as well as in vitro drug follicular penetration, comparing the results with the ones obtained for the reference industrial product.

\section{Materials and Methods}

\section{Materials}

Magistral topical solutions containing 5\% of minoxidil were purchased from three magistral pharmacies located in Rio Grande do Sul, Brazil, and identified as A, B and C. The industrial reference medication (Aloxidil ${ }^{\circledR}$, Theraskin, Brazil) was purchased from a local drugstore. Minoxidil base was obtained from Fagron (Brazil). The samples were kept in the original packaging at room temperature and protected from light and humidity until the tests were performed. The other materials used were analytical grade methanol (Qhemis, Brazil) propylene glycol (Delaware, Brazil) and purified water.

\section{Physicochemical characterization}

Magistral and industrial solutions were first evaluated regarding their organoleptic properties, resistance to centrifugation, $\mathrm{pH}$ and mass density according to Brazilian pharmacopoeia and the national health surveillance guidelines [9,10,11]. All analysis were performed in triplicate.

The homogeneity, color, transparency, odor and apparent viscosity of the magistral and industrial samples were evaluated by visual appearance. Regarding the resistance to centrifugation, the solutions were placed in falcon tubes and centrifuged at $3000 \mathrm{rpm}$ for 30 minutes. After that, they were 
visually analyzed, checking whether there were changes. Such test is preconized as pre-stability determination [10]. For $\mathrm{pH}$ determination, the topical solutions were placed in contact with a calibrated electrode, without previous dilution. Aiming determination of mass density, the relative density was determined using a $5 \mathrm{~mL}$ pycnometer. Initially, the formulations and a sample of purified water were set at a temperature of $25^{\circ} \mathrm{C}$. The empty pycnometer was weighed and then filled with purified water and weighed again. The process was repeated with the samples. To determine the mass density, the water density at $25{ }^{\circ} \mathrm{C}$ and the relative density determined were taken into account.

Then, the drug content was determined. For the quantification of minoxidil in the topical solutions, the ultraviolet spectrophotometry method was used, measuring the absorbance at $285 \mathrm{~nm}$, according to a previously validated method [5].

To confirm the suitability of the method, the linearity in the range from $3-15 \mu \mathrm{g} / \mathrm{mL}$ was determined, as well as the method specificity, which was assessed evaluating the placebo (solution containing all adjuvants except for the drug). To prepare the samples, the minoxidil base substance was diluted in methanol (first dilution) and purified water (second dilution). For the magistral and industrial topical solutions, $1.4 \mathrm{~mL}$ of the samples were transferred into a 100 $\mathrm{mL}$ volumetric flask containing $10 \mathrm{~mL}$ of methanol, which was placed in the ultrasound bath for 5 minutes. After that, the volume was adjusted with purified water. A second dilution in water was performed to reach a concentration of 7 $\mu \mathrm{g} / \mathrm{mL}$ of minoxidil. The obtained concentration values of the samples were compared to the theoretical concentration, obtaining the value of drug content in percentage. The samples considered approved were the ones presenting from $90 \%$ to $110 \%$ of the labeled amount of minoxidil [12].

\section{Comparison of indicated dosage}

For comparison of the indicated dosage of the formulations, the volumes corresponding to the dosage indicated by the pharmacies and by the medication package insert of the industrial product were determined in triplicate. Thus, for the magistral samples, the amount of 20 drops was weighed from a vertical drip (considered the most suitable for dropper bottles) as well as from a horizontal drip (more easily performed by the patients). For the industrial sample, the amount of 6 jets was weighed. The mass value was converted to volume using the mass density previously determined.

\section{In vitro follicular penetration of minoxidil}

Pork ears, obtained from a local slaughterhouse, were sanitized with sodium lauryl sulfate solution $(0.5 \%)$ and the hair was removed with a razor blade, gently applied to the skin surface. Then, the outermost layer of the skin was removed from the cartilage with the aid of the scalpel, and cut into circles of between $0.06 \mathrm{~cm}$ and $0.11 \mathrm{~cm}$ thick. The skin samples were frozen at $-4^{\circ} \mathrm{C}$ in aluminum foil until use, which did not exceed 2 months.

Follicular penetration of minoxidil from different topical solutions were evaluated using Franz diffusion Cell in triplicate. The skin sample was placed between the donor and the receptor compartments. The receptor compartment was filled with $18 \mathrm{~mL}$ of purified water. In the donor compartment, $2 \mathrm{~mL}$ of minoxidil topical solution was added. The apparatus was maintained at $32^{\circ} \mathrm{C}$ and under stirring for $5 \mathrm{~h}$. After that, the amount of minoxidil that remained in the hair follicles was assessed using differential tape stripping [13]. The skin sample was removed from the Franz cell and the stratum corneum was removed with the aid of 15 adhesive tapes. The follicular content was then removed by applying a drop of cyanoacrylate glue. A piece of tape was placed over the glue and it was slightly pressed for $5 \mathrm{~min}$. The tape was then removed and the dried glue layer adhered to the tape was transferred to a glass tube from which minoxidil was extracted by the addition of $5 \mathrm{~mL}$ of methanol with ultrasound bath for a period of $40 \mathrm{~min}$. The drug content was analyzed at $285 \mathrm{~nm}$ by UV spectrophotometer. The amount of minoxidil that was kept in the hair follicles was calculated by a standard curve obtained with minoxidil base solubilized in methanol $(3,5,7,10$ e $15 \mu \mathrm{g} / \mathrm{mL})$. An experiment applying the placebo (solution containing all adjuvants except for the drug) was also performed.

\section{Statistical analysis}

The statistical analysis was performed by analysis of variance, followed by Dunnett's test, when a significant difference was detected $(\alpha=0.05)$.

\section{Results and Discussion}

\section{Composition of formulations}

The compositions of the formulations evaluated in this study are described in Table 1. The industrial topical solution, considered reference in the Brazilian market, is composed of minoxidil base, propylene glycol (co-solvent) and a hydroalcoholic vehicle. The active minoxidil in base form is chemically presented as 3-hydroxy-2-imino-6-piperidin-1ylpyrimidin-4-amine $\left(\mathrm{C}_{9} \mathrm{H}_{15} \mathrm{~N}_{5} \mathrm{O}\right)$, with a molecular weight of $209.5 \mathrm{~g} / \mathrm{mol}$, CAS of 38304-91-5 and DCB number of 05980. It is a crystalline, off-white solid, soluble in acid and propylene glycol solutions, poorly soluble in alcohols and insoluble in water, acetone and alkaline solutions [14,15].

Table 1: Composition of minoxidil topical solutions according to the manufacturer's declaration $(\mathrm{A}=$ magistral sample $\mathrm{A}, \mathrm{B}=$ magistral sample $\mathrm{B}, \mathrm{C}=$ magistral sample $\mathrm{C}$, Reference $=$ industrial reference product). Water is used as solvent to reach $100 \%$.

\begin{tabular}{cccc}
\hline Sample & Minoxidil & $\begin{array}{c}\text { Propylen } \\
\text { e glycol }\end{array}$ & $\begin{array}{c}\text { Ethano } \\
\mathbf{l}\end{array}$ \\
\hline $\mathrm{A}$ & $\begin{array}{c}5 \% \\
\text { (minoxidil sulfate) } \\
\mathrm{B}\end{array}$ & $3 \%$ & $30 \%$ \\
$\mathrm{C}$ & $\begin{array}{c}5 \% \\
\text { (minoxidil sulfate) }\end{array}$ & $5 \%$ & $70 \%$ \\
Reference & $\begin{array}{c}5 \% \\
\text { (minoxidil sulfate) } \\
5 \%\end{array}$ & $10 \%$ & $50 \%$ \\
& NI* & $\mathrm{NI}$ \\
\hline
\end{tabular}

* NI: Not informed

The magistral solutions are formulations composed of minoxidil sulfate, propylene glycol and a hydroalcoholic vehicle. According to the certificate of analysis, minoxidil 
sulfate is a salt $\left(\mathrm{C}_{18} \mathrm{H}_{30} \mathrm{~N}_{10} \mathrm{O}_{2} \cdot \mathrm{H}_{2} \mathrm{SO}_{4}\right)$, presenting molecular weight of $516.58 \mathrm{~g} / \mathrm{mol}$, CAS of $83701-22-8$ and DCB number of 09761 . Due to salt formation, the solubility of the active is favored.

\section{Evaluation of physicochemical characteristics}

The magistral and the industrial samples were evaluated according to their physicochemical properties (Table 2). Regarding the color, the reference sample was light yellow, while the magistral samples were colorless. This may be justified by the minoxidil in the base form used in the industrial solution, which is a slightly yellowish powder. The minoxidil sulfate, on the other side, presents a white color. The magistral and the industrial solutions were homogeneous and clear, but the reference industrial product presented air bubbles, which can be due to the spray present in the industrial packing, while the magistral solutions are placed in dropper bottles.

Table 2: Physicochemical properties of the minoxidil topical solutions $(\mathrm{A}=$ magistral sample $\mathrm{A}, \mathrm{B}=$ magistral sample $\mathrm{B}, \mathrm{C}=$ magistral sample $\mathrm{C}$, Reference $=$ industrial reference product)

\begin{tabular}{ccccc}
\hline Tests & A & B & C & Reference \\
\hline Color & Colorless & Colorless & Colorless & Light yellow \\
Homogeneity & Homogeneous & Homogeneous & Homogeneous & $\begin{array}{c}\text { Homogeneous } \\
\text { with air bubbles }\end{array}$ \\
Transparency & Clear & Clear & Clear & Clear \\
Odor & $\begin{array}{c}\text { Ethanol and } \\
\text { propylene glycol }\end{array}$ & Ethanol & Ethanol & $\begin{array}{c}\text { Ethanol and } \\
\text { propylene glycol }\end{array}$ \\
Viscosity & Low & Low & Low & Low to medium \\
pH & $2.61 \pm 0.02$ & $2.80 \pm 0.02$ & $2.78 \pm 0.01$ & $8.04 \pm 0.02$ \\
$\begin{array}{c}\text { Density }(\mathrm{g} / \mathrm{mL}) \\
\text { Resistance to } \\
\text { centrifugation }\end{array}$ & $0.9813 \pm 0.001$ & $0.9103 \pm 0.0008$ & $0.9208 \pm 0.0006$ & $1.0039 \pm 0.0017$ \\
$\begin{array}{c}\text { Minoxidil } \\
\text { content }(\%)\end{array}$ & No changes & No changes & No changes & No changes \\
\hline
\end{tabular}

The magistral sample A presented an odor which is characteristic of ethanol and a slight propylene glycol odor, while for the magistral samples B and C only ethanol odor was noticed, which is due to the higher ethanol percentage. Regarding the industrial sample, odor of propylene glycol and ethanol were noticed. Such solution, since it is composed of minoxidil base, supposedly requires a greater amount of propylene glycol for active solubilization, when compared to the magistral formulations that use minoxidil sulfate [15]. Also, a higher viscosity of the industrial solution was observed compared to the magistral samples, which indicates a higher amount of propylene glycol, since such substance is a slightly viscous raw material.

Regarding the $\mathrm{pH}$ of the solutions, it is noted that the magistral samples $\mathrm{A}, \mathrm{B}$ and $\mathrm{C}$ presented acidic $\mathrm{pH}$, significantly lower than the reference sample, which presented basic $\mathrm{pH}$, due to the structural difference in the active molecule used in the different formulas. Due to the low $\mathrm{pH}$ of the magistral products, some adverse reactions may appear throughout the treatment, such as dermatitis, peeling and irritation [16]. Minoxidil is stable above $\mathrm{pH} 2.0$ [17].

Since the monoxidil topical solutions are hydroalcoholic, the determination of density may indicate the amount of ethanol in the formulation. All magistral samples presented significantly lower density than the industrial product. It can be seen that magistral sample $B$, with the highest ethanol content, presented the lowest density, the opposite being observed for the magistral solution A. Since the amount of ethanol in the industrial product is not known, it is assumed, by the density presented, that the ethanol concentration in this product is lower than in the magistral formulas. Moreover, the density value observed for the reference product is also probably related to a greater amount of propylene glycol in such sample, which has a density of around 1.035 [9].

Regarding the resistance to centrifugation, none of the samples showed signs of instability at the end of the test, indicating that the products have a tendency to remain physically stable throughout storage due to the addition of solvents and co-solvents. The centrifugation test is used to predict possible formulation instabilities such as precipitation, which could occur in this study due to incorrect solubilization of the drug and formation of precipitates [11]. The analytical method used to evaluate the minoxidil content in the topical solutions presented adequate linearity and specificity, since a solution composed of water, ethanol and propylene glycol showed no absorbance at $285 \mathrm{~nm}$ and correlation values greater than 0.99 were observed. The industrial samples and the magistral sample $\mathrm{C}$ showed a percentage of around $98 \%$ of the theoretical minoxidil concentration, without significant differences, while for the magistral samples A and B significant lower percentages were found (close to 80\%). According to the American pharmacopeia, only the industrial product and the magistral sample $\mathrm{C}$ presented concentration of minoxidil within the specification [12]. 
When using a salt or an ester of a raw material instead of its base, the correction factor should be determined. Therefore, it can be suggested that such correction during the weighting process of the active was not performed by the magistral pharmacies A and B. Other quality deviation factors may also have led to the low active concentration in the solutions, such as weighing error, lack of balance calibration, improper storage of raw materials, substance degradation, among others [16].

\section{Comparison of indicated dosage}

The volume of solution to be applied on the scalp was evaluated according to the dosage indicated by the manufacturer in drops (using the vertical and horizontal dropper) or in jets. The results are described in Figure 1. According to the information found in the package leaflet of the reference product, 6 jets of the drug solutions should be applied, which corresponded to around $1 \mathrm{~mL}$. For the magistral samples, it was followed the indication of the magistral pharmacies which manipulated the formulas, where the usual dose was 20 drops/day. It was observed that, in the horizontal position, all magistral products led to higher solution volumes compared to the vertical position, but both the horizontal and vertical positions lead to significant lower volumes compared to the volume indicated by the reference product package leaflet.

When evaluating the amount of minoxidil at each dosage considering the concentration of active described on the labels $(50 \mathrm{mg} / \mathrm{mL}), 6$ jets of the industrial product correspond to around $50 \mathrm{mg}$ of minoxidil, while 20 drops of the magistral solutions correspond to around $30 \mathrm{mg}$ of minoxidil. The indicated dosage of the industrial product corresponds to a considerable greater amount of drug in relation to the dosage indicated by the pharmacies. It should also be considered that the package leaflet describes that the industrial reference product can be applied up to 2 times a day. The lower dosage indication for the magistral minoxidil topical solutions, besides a lower drug content, compared to the reference industrial product, can lead to therapeutic ineffectiveness.

The lack of standardization of the number of drops per $\mathrm{mL}$ of solutions produced in magistral pharmacies may have been a factor affecting the dose quantities. Different alcohol degrees at different temperature significantly change the volume of a drop, making it necessary to standardize cannulas to ensure accuracy during use [18]. Since the magistral solutions contain a high amount of ethanol, the amount of drops per $\mathrm{mL}$ changes according to the percentage of the constituent and also according to the other inputs present in the formula. The magistral product A presented a greater volume from 20 drops than the solutions B and C, which have greater amount of ethanol in their formulations.

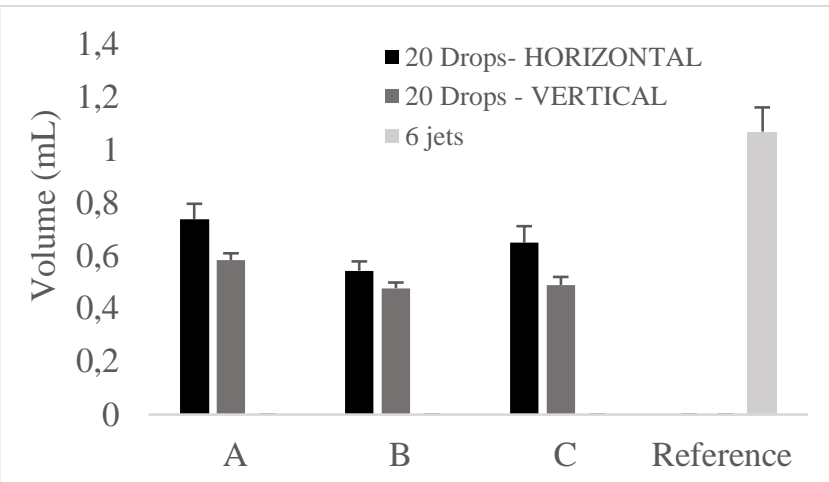

Figure 1: Volume of minoxidil topical solution to be applied on the scalp according to the indicated dosage $(\mathrm{A}=$ magistral sample $\mathrm{A}, \mathrm{B}=$ magistral sample $\mathrm{B}, \mathrm{C}=$ magistral sample $\mathrm{C}$, Reference $=$ industrial reference product). All samples were statistically different from the reference.

\section{In vitro follicular penetration of minoxidil}

Aiming clinical efficacy, topically applied drugs or cosmetic actives depend not only on their pharmacological properties, but also on their release from the vehicle, their penetration into the stratum corneum or other skin layers as well as their availability at the site of action [19]. Minoxidil, when applied topically, should permeate the percutaneous layer, but it should not permeate the entire skin, only reach the follicle bulb, thus preventing it from reaching the bloodstream. The minoxidil topical solutions used in this study were tested to assess the potential for follicular penetration of the active and the results are described in Figure 2. The results were calculated by discounting the value obtained for the placebo from the values obtained for the samples.

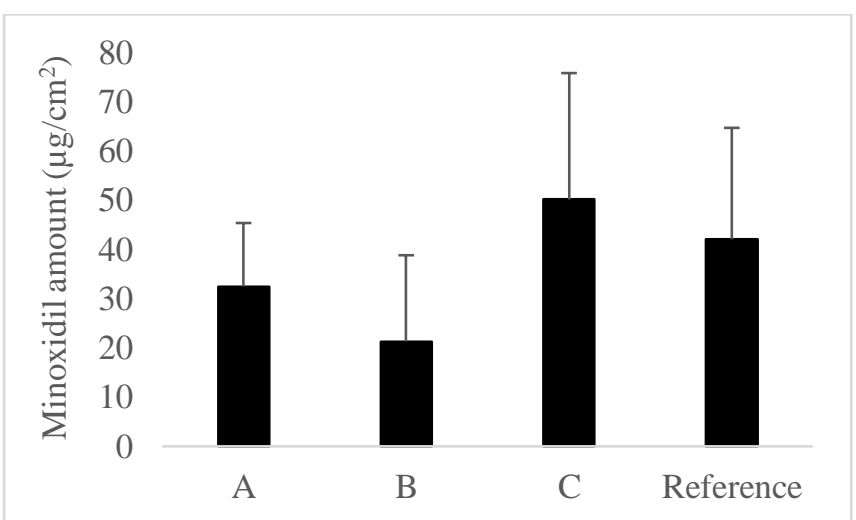

Figure 2. Evaluation of in vitro follicular penetration of minoxidil from topical solutions $(\mathrm{A}=$ magistral sample $\mathrm{A}, \mathrm{B}=$ magistral sample $\mathrm{B}, \mathrm{C}=$ magistral sample $\mathrm{C}$, Reference $=$ industrial reference product $)$. All samples were statistically equal to the reference.

Comparing the follicular penetration of minoxidil applied from the magistral topical solutions with the reference sample, there are no significant differences (Figure 2). The low number of replicates and the high variability of such skin experiment may have contributed to the lack of statistical difference. Therefore, in the conditions of evaluation, the magistral topical solutions were able to promote the follicular penetration of minoxidil in a similar way as the reference 
product, even though the magistral products $\mathrm{A}$ and $\mathrm{B}$ presented below-labeled drug content.

Although no differences were found in the present investigation, it should be taken into account that, some factors, besides the lower drug content, may harm the minoxidil skin permeation or penetration into the hair follicles when in normal use conditions, considering the magistral samples. One of them is the considerable lower dosage indication (Figure 1), which was not considered in this experiment, since all donor compartments received the same volume of different topical solutions containing minoxidil. The other factor is the higher amount of ethanol, which increases the tendency of the drug to revert to an insoluble crystalline form when ethanol evaporates, thus possibly affecting it's absorption through the skin [20]. At last, it should be considered that minoxidil sulfate, when solubilized, becomes ionized, presenting probably lower capacity of transcutaneous absorption compared to minoxidil base.

Several studies have been devoted to the development of formulations aiming to increase minoxidil skin permeation and/or penetration into the hair follicles. Pereira and coworkers (2016) developed solid effervescent formulation of minoxidil sulfate, demonstrating an increase in the drug permeation highly dependent on the concentration of the effervescent mixture in the formulation [21]. Mura and coworkers (2013) studied the influence of penetration enhancing vesicles on transdermal minoxidil administration. In vitro diffusion experiments confirmed that vesicle formulations with penetration enhancers promoted greater drug deposition on the skin [22]. Matos and co-workers (2015) described that chitosan nanoparticles increased approximately 2 fold the penetration of minoxidil sulfate into the hair follicles, compared to the control [23]. Abd and coworkers (2018) developed nanoemulsions containing eucalyptol or oleic acid, which enhanced the skin permeation of minoxidil, besides increasing the deposition of the substance in the hair follicles [24].

\section{Conclusions}

The minoxidil topical solutions from magistral pharmacies presented differences compared to the industrial product in the quality parameters evaluated. Regarding the differences that can directly influence the efficacy and safety, the lower $\mathrm{pH}$, the lower minoxidil content, and the lower indication of dosage to be applied in the hair follicles should be pointed out. Regarding in vitro follicular penetration, however, no statistical differences were found.

\section{Conflict of interest}

The authors declare no conflicts of interest.

\section{References}

1. Sampaio SAP, Rivitti EA. Dermatologia. 3 ed. São Paulo: Artes Médicas; 2008.

2. Hanneken S, Ritzmann S, Nöthen MM, Kruse R. Androgenetic alopecia. Current aspects of a common phenotype. Der Hautarzt. 2003; 54:703712.
3. Rossi A, Anzalone A, Fortuna MC, Caro G, Garelli V, Pranteda G, Carlesimo M. Multi-therapies in androgenetic alopecia: review and clinical experiences. Dermatol Ther. 2016; 29:424-432.

4. Adil A, Godwin M. The effectiveness of treatments for androgenetic alopecia: A systematic review and meta-analysis. J Am Acad Dermatol. 2017; 77:136141.

5. Zaheer ZA, Mirza S, Moazzam I, Sayad IW. UVSpectrophotometric determination of minoxidil and its application to the assay in pharmaceutical dosage forms. Der Pharma Chemica. 2012; 04:568-573.

6. Ferreira AO, Brandão MF, Silva MADCC. Guia Prático da Farmácia Magistral. 2 ed. Juiz de Fora; 2002.

7. Bonfilio R, Emerick GL, Júnior AN, Salgado HRN. Farmácia magistral: sua importância e seu perfil de qualidade. Rev Bai Sau Pub. 2010; 34:653-664.

8. Agência Nacional de Vigilância Sanitária. Resolução da Diretoria Colegiada nr. 67. Brasília, DF; 2007 Oct. Diário Oficial da República Federativa do Brasil.

9. Farmacopeia Brasileira. 5. ed. Brasília: Anvisa; 2010.

10. Guia de Estabilidade de Produtos Cosméticos. Brasília: Anvisa; 2004.

11. Guia de Controle de Qualidade de Produtos Cosméticos. Brasília: Anvisa; 2007.

12. The United States Pharmacopeia. 42 ed. Rochville: United States Pharmacopoeial Convention, 2019.

13. Teichmann A, Jacobi U, Ossadnik M, Richter H, Koch S, Sterry W, Lademann J. Differential stripping: determination of the amount of topically applied substances penetrated into the hair follicles. J Invest Dermatol. 2005; 125: 264-269.

14. Swetmann, S. Martindale: The Complete Drug Reference. 34 ed. London:Pharmaceutical Press; 2005.

15. Sousa RA, Cavalheiro ETG. Determinação de minoxidil em formulações farmacêuticas usando permanganometria. Ecl Quim. 2009; 34:41-49.

16. Silva RF. Indicadores de desempenho em sistemas de garantia de qualidade de produção de medicamentos uma contribuição para aplicação em Farmácias de Manipulação [dissertation] Niterói: Universidade Federal Fluminense; 2007.

17. García B, Arcos J, Domingo PL, Leal JM. Acid-base equilibria of minoxidil. Analytical Letters. 1990; 24: 391-411. 
18. Ferraz H, Camargo CM, Silva MG Ferraz HG, Gutierrez MA. Avaliação de diferentes acessórios gotejadores utilizados na preparação de medicamentos homeopáticos. Rev Bras Farm. 2009; 90: 154-158.

19. Zsikó S, Csányi E, Kovács A, Budai-Szucs M, Gácsi A, Berkó S. Methods to evaluate skin penetration In Vitro. Sci Pharm. 2019; 87:19.

20. Mali N, Darandale S, Vavia P. Niosomes as a vesicular carrier for topical administration of minoxidil: formulation and in vitro assessment. Drug Deliv Transl Res.2013; 3: 587-92.

21. Pereira MN, Schulte HL, Duarte N, Lima EM, SáBarreto LL, Gratieri T, Gelfuso GM, Cunha-Filho MSS. Solid effervescent formulations as new approach for topical minoxidil delivery. Eur J Pharm Sci. 2016; 96:441-419.

22. Mura S, Manconi M, Fadda AM, Sala MC, Perricci J, Pini E, Sinico C. Penetration enhancer-containing vesicles (PEVs) as carriers for cutaneous delivery of minoxidil: in vitro evaluation of drug permeation by infrared spectroscopy. Pharm Dev Technol. 2013; 18:1339-1345.

23. Matos BN, Reis TA, Gratieri T, Gelfuso GM. Chitosan nanoparticles for targeting and sustaining minoxidil sulphate delivery to hair follicles; Int $\mathbf{J}$ Biol Macromol. 2015; 75:225-229.

24. Abd E, Heather AE, Benson MSR, Grice JE. Minoxidil skin delivery from nanoemulsion formulations containing eucalyptol or oleic acid: Enhanced diffusivity and follicular targeting. Pharmaceutics. 2018; 10:19. 